\title{
Screening and characterisation of gamma-aminobutyric acid (GABA) producing lactic acid bacteria isolated from Thai fermented fish (Plaa-som) in Nong Khai and its application in Thai fermented vegetables (Som-pak)
}

\author{
Varavut TANAMOOL ${ }^{1}$, Piyorot HONGSACHART' ${ }^{2}$, Wichai SOEMPHOL ${ }^{2,3 *}$
}

\begin{abstract}
This study aimed to evaluate the capability of lactic acid bacteria (LAB) isolated from different kinds of fermented fish products (Plaa-som) on the production of $\gamma$-aminobutyric acid (GABA). Among them, isolate L10-11, identified as Lactobacillus plantarum, offered the highest GABA production and was selected for further study. The highest production of GABA was obtained within $48 \mathrm{~h}$ from the de Man, Rogosa and Sharpe (MRS) medium, having a pH range of 5-6. Increasing the monosodium glutamate (MSG) concentration resulted in a higher accumulation of GABA and reached the highest concentration (15.74 g/L) using $4 \%$ (w/v) MSG, while high residual MSG was also observed in accordance with concentration increase. On the other hand, the addition of $\mathrm{NaCl}$ in the culture medium by up to $7 \%$ (w/v) did not suppress GABA production. Preliminary application of strain L10-11 as starter producing GABA was investigated in Thai fermented vegetables (Som-pak). It was found that GABA formation could be observed increasingly following the concentration of MSG added. GABA content in Som-pak was 5 times higher than that of control when inoculating Lb. plantarum L10-11 and adding MSG at $1 \%$ (w/v). In addition, sensory evaluation revealed that addition of this starter culture to Som-pak gave overall acceptability slightly higher than that which allowed fermentation to occur spontaneously. This alternative procedure would be successful for improving the nutritional quality of functional fermented food.
\end{abstract}

Keywords: lactic acid bacteria; GABA; fermented fish; Plaa-som; Som-pak.

Practical Application: Lb. plantarum L10-11 isolated from plaa-som has great potential starter cultures for improvement the quality of Som-pak by enhancing GABA content in the Som-pak.

\section{Introduction}

Gamma-aminobutyric acid (GABA) is a non-protein amino acid produced through the decarboxylation of glutamate by glutamate decarboxylase and wildly distributes among animals, plants and microorganisms (Ueno, 2000). GABA possesses well-known beneficial bioactivities such as neurotransmission, the induction of hypertension and a tranquilising effect (Pearl et al., 2006). In addition, it can stimulate immune cells (Oh et al., 2003) and is involved in the treatment of sleeplessness, depression and autonomic disorders (Okada et al., 2000) as well as the improved prevention of diabetes (Hagiwara et al., 2004). This results in increasing commercial demand and extensive study to synthesis GABA in large amounts (Choi et al., 2006; Plokhov et al., 2000). However, the direct addition of GABA to food is considered unsafe and unnatural, while the utilisation of GABA-rich foods produced by natural techniques is more favourable (Dhakal et al., 2012). Many microorganisms are able to produce GABA, including bacteria, fungi and yeast. Among them, lactic acid bacteria (LAB) have been given more attention in research because of their utilisation in the food industry and the fact they are generally regarded as safe (GRAS) and known as probiotic. The production of GABA by LAB in fermented products can provide alternative, naturally fermented health products.

Currently, LAB has been screened and characterised from various sources having different GABA-producing ability varied among different species and strains, such as Lactobacillus buchneri isolated from kimchi (Cho et al., 2007), Lactobacillus paracasei from fermented fish (Komatsuzaki et al., 2005), Lb. plantarum from cheese (Siragusa et al., 2007), Lactococcus lactis isolated from Kimchi and Youghurt (Lu et al., 2008), and Lb. futsaii from Thai fermented shrimp (Kung-Som) (Sanchart et al., 2017).

In several fermented products, GABA is generated by LAB during the fermentation of different kinds of food such as kimchi (Cho et al., 2007), black raspberry juice (Kim et al., 2009), black soybean milk (Ko et al., 2013), and Nham (Thai fermented pork sausage) (Ratanaburee et al., 2013). Yields of GABA are affected by several factors, including initial $\mathrm{pH}$, concentration

${ }^{1}$ Chemistry Program, Faculty of Science and Technology, Nakhon Ratchasima Rajabhat University, 30000, Nakhon Ratchasima, Thailand

${ }^{2}$ Faculty of Applied Science and Engineering, Nong Khai Campus, Khon Kaen University, 43000, Nong Khai, Thailand

${ }^{3}$ Department of Biotechnology, Fermentation Research Center for Value Added Agricultural Products - FerVAAP, Faculty of Technology, Khon Kaen University, 40002, Khon Kaen, Thailand

*Corresponding author: wichso@kku.ac.th 
of glutamic, temperature, and incubation time (Li et al., 2010). Extensive studies have been conducted on optimisation in order to increase the efficiency of the GABA production process (Lu et al., 2008; Li et al., 2010; Shan et al., 2015).

Many GABA-producing LAB strains have been isolated and identified. However, further isolation and characterisation research is required because screening various types of GABA-producing LAB is important for the food industry (Komatsuzaki et al., 2005). In further screening, isolation sources should be expanded to include as many fermented foods as possible to obtain GABA-producing LAB strains that may have specific fermentation profiles. This will lead to a wider application field and higher flexibility of starter cultures in addition to achieving a safe and consistent quality product. In this study, the researchers attempted to screen LAB-producing GABA from several kinds of fermented fish (Plaa-som) produced in Nong Khai province, Thailand. The selected isolate was then identified and characterised for capability in GABA production. Moreover, preliminary investigation for use as a pure starter culture in novel Thai fermented vegetable products (Som-pak) was also carried out.

\section{Materials and methods}

\subsection{Selection of $G A B A$-producing $L A B$}

A total of $44 \mathrm{LAB}$ strains were used in this study, which were isolated from various Thai fermented fish (Plaa-som) in the fresh market at Nong Khai province, Thailand as reported previously (Hongsachart, 2016). The stock cultures kept at $-80^{\circ} \mathrm{C}$ were streaked on MRS agar and incubating at $30^{\circ} \mathrm{C}$ for $18 \mathrm{~h}$. Single colony of fresh culture was then inoculated into MRS broth containing 3.0\% (w/v) of monosodium glutamate (MSG). All cultures were incubated under static conditions at $30{ }^{\circ} \mathrm{C} 72 \mathrm{~h}$ and the culture supernatant was then collected by centrifugation at 2,400 $\mathrm{x} g$ for $10 \mathrm{~min}$. Subsequently, each sample was examined for the presence of GABA using thin layer chromatography (TLC) and spectrophotometric methods, as described below. For cell growth, Lb. plantarum L10-11 was cultivated in MRS containing $1 \%(\mathrm{v} / \mathrm{v})$ inoculum at $30^{\circ} \mathrm{C}$. Growth of the isolate was determined by measuring culture turbidity at $600 \mathrm{~nm}$, while culture $\mathrm{pH}$ was also measured at this time (the same time intervals). Viable cells were measured by plate count using MRS agar medium.

\subsection{Effect of culture medium on GABA production}

To determine the effect of culture medium condition on GABA production, the researchers selected three parameters including the concentration of MSG, $\mathrm{NaCl}$, and initial $\mathrm{pH}$. MSG concentration at $0.5-5 \%(\mathrm{w} / \mathrm{v})$ was included in the MRS medium. To test the effect of $\mathrm{NaCl}, \mathrm{NaCl}$ was added at $1-7 \%(\mathrm{w} / \mathrm{v})$ to MRS broth containing 3\% MSG. In order to study the effect of initial $\mathrm{pH}$ on the GABA production, MRS medium containing $3 \% \mathrm{MSG}$ at the initial $\mathrm{pH}$ values of 4.0, 5.0, 6.0, 7.0, and 8.0 were used for cultivation of Lb. plantarum L10-11.

The pre-culture was prepared in MRS medium at $30^{\circ} \mathrm{C}$ for $24 \mathrm{~h}$ and transferred to the tested medium described above at a concentration of $1 \%(\mathrm{v} / \mathrm{v})$ for $72 \mathrm{~h}$. The culture supernatant was obtained by centrifugation at 2,400 $\mathrm{x}$ g for $10 \mathrm{~min}$ and kept at $-20^{\circ} \mathrm{C}$ until used. The independent experiment were conducted in triplicate.

\subsection{Thin Layer Chromatography (TLC) for identification of $G A B A$}

Levels of GABA were determined qualitatively by TLC using the method of Choi et al. (2006) with an aluminium TLC plate (Sigma-Aldrich Co., Germany). Culture supernatant was obtained by centrifugation at $2,400 \mathrm{x} g$ for $10 \mathrm{~min}$. The two microliters of supernatant was then spotted onto TLC plates compared with $1 \%(\mathrm{w} / \mathrm{v})$ of standard GABA and MSG solution. TLC was conducted using an acetic acid: $n$-butanol: distilled water (4:1:1) solvent mixture as the mobile phase. Subsequently, the plates were sprayed with $1.0 \%(\mathrm{w} / \mathrm{v})$ ninhydrin solution and then heated at $70{ }^{\circ} \mathrm{C}$ for $5-10 \mathrm{~min}$ until spots appeared.

\subsection{Quantification of GABA content}

GABA content was determined by the method of Watchararparpaiboon et al. (2010). Briefly, the mixture of solution ( $0.2 \mathrm{M}$ borate buffer, $0.2 \mathrm{~mL}$ : $6 \%$ phenol reagent, $1 \mathrm{~mL}$ ) was added to the supernatant $(0.1 \mathrm{~mL})$. Afterwards, $0.4 \mathrm{~mL}$ of $7.5 \%$ sodium hypochlorite was added and boiled for $10 \mathrm{~min}$. The sample was immediately cooled for $5 \mathrm{~min}$ and the optical density measured at $630 \mathrm{~nm}$. Calibration curve of standard GABA was prepared with the range concentration of $0.5-4 \mathrm{~g} / \mathrm{L}$ giving coefficient of determination $\left(\mathrm{R}^{2}\right)$ of 0.99 and used to determine the concentration of GABA in the samples.

\subsection{LAB identification}

The LAB isolates were cultured on MRS medium at $30^{\circ} \mathrm{C}$ for $24 \mathrm{~h}$. The cell cultures were then harvested by centrifugation and subsequently subjected to isolation of chromosomal DNA according to previous reports (Soemphol et al., 2008) and used as template for PCR by using iTaq ${ }^{\mathrm{TM}}$ (iNtRON BIOTECHNOLOGY Inc., Korea) with a pair of universal primer $27 \mathrm{f}$ and $1492 \mathrm{r}$. The PCR products of approximately $1.5 \mathrm{~kb}$ were obtained and further purified using Clean Kit (NucleoSpin ${ }^{\circledR}$ Gel and PCR Clean-up, MACHEREY-NAGEL GmbH \& Co. KG) before sequence analysis (Cosmogenetech Co, Ltd, Korea). Multiple alignments of the sequences determined were performed with the CLUSTALW program (Thompson et al., 1994), while the neighbour-joining phylogenetic tree was constructed using Mega 6.0 version with 1000 bootstrap replicates (Tamura et al., 2013).

\subsection{Production of high GABA Thai sauerkraut (Som-pak)}

Som-pak was prepared following a local recipe. Cabbage and green onion were purchased at a local market in Muang, Nong Khai. After washing and peeling, they were cut into small pieces. Cabbage and green onion with a 1:1 ratio by weight was mixed with salt and crushed properly until soft, after which it was washed three times with tap water. The sample was stored in plastic baskets for $3 \mathrm{~h}$ to drain excess water and then put into a plastic bag. Boiled rice water $(100 \mathrm{~g}$ rice $/ 100 \mathrm{~mL}$ water $)$ after filtration with a cotton cloth was added in a 1:1 ratio of 
vegetables with a final salt concentration of $3 \%(w / w)$. In order to investigate the effect of inoculum and MSG concentration to GABA production, the inoculum of $L b$. plantarum L10-11 was prepared by growing on MRS for $24 \mathrm{~h}$ and collected by centrifugation, after which it was washed twice with normal saline. Cell suspension was adjusted to $10^{6} \mathrm{CFU} / \mathrm{g}$ of raw materials compared to the normal procedure without pure LAB starter. MSG was added into Som-pak at a concentration of $0.1,0.3$, and $1.0 \%(\mathrm{w} / \mathrm{w})$. Fermentation was carried out in triplicate using closed plastic bags incubated at $30^{\circ} \mathrm{C}$ for 5 days. The homogenate samples were collected and used for monitoring of cell viability, while the supernatant obtained by centrifugation was used for determination of $\mathrm{pH}$, acidity and GABA content, as described above.

\subsection{Determination of antioxidant activity}

The supernatant of homogenate Som-pak samples were extracted by distilled water prior to the determination of antioxidant activity. The free radical scavenging activity was measured by the DPPH method modified from Li et al. (2018). In brief, $3 \mathrm{~mL}$ of $3 \% \mathrm{w} / \mathrm{v}$ of DPPH solution was added to $0.1 \mathrm{~mL}$ of each sample. The aliquot samples were vigorously mixed and kept at room temperature in dark conditions for $30 \mathrm{~min}$. Absorbance was measured by UV-vis spectrophotometer at a maximum absorbance of $515 \mathrm{~nm}$. The antioxidant activities were exhibited as Vitamin $\mathrm{C}$ equivalent antioxidant capacity (VCEAC) in $\mathrm{mg} / \mathrm{L}$, while antioxidant activity was calculated via the calibration curve of the standard for vitamin $\mathrm{C}$.

\subsection{Data analysis}

Data of GABA contents, pH, acidity, log CFU/mg and sensorial properties of Som-pak were subjected to analysis of variance (ANOVA). Comparison of the mean values was carried out using Duncan's multiple range test. Moreover, the detailed VCEAC was further analysed by simultaneous Student's t-tests comparing 0 day and 5 days of fermentation time of Som-pak in each concentration of MSG, establishing a 5\% level for rejection of the null hypothesis. Data were analyzed with SPSS v. 2009.

\subsection{Sensory evaluation}

The sensorial properties of Som-pak were evaluated for colour, texture, odour, flavour and sourness, and overall acceptance by 30 panellists. A 9-point hedonic scale was used for sensory evaluation (Cho et al., 2011). The samples with three-digit random members were served on a white paper plate at room temperature. Panellists were instructed to rinse their mouths with water before starting and between sample evaluations (Ratanaburee et al., 2013).

\section{Results and discussion}

\subsection{Selection and identification of GABA-producing $L A B$}

To screen the potential LAB producing GABA, various LAB previously isolated from Thai fermented fish products (plaa-som) (Hongsachart, 2016) were cultured in MRS containing 3\% MSG for 3 days. Among $44 \mathrm{LAB}$, the isolates L10-11 clearly produced the highest GABA based on the TLC results (data not show), which is consistent with high adsorption at $630 \mathrm{~nm}$ after reaction, as described in the Materials and Methods. This isolate was a Gram-positive strain of the rod cell type and formed creamy, opaque, and circular colonies on MRS plates. The 16S rRNA nucleotide sequence of this isolate showed $99 \%$ homology with that of Lactobacillus plantarum. Accordingly, the strain was designated as Lb. plantarum L10-11 and used for further study (Figure 1). Several researchers have found $L b$. plantarum to be a dominant strain during the last stage of fermentation of Thai fermented fish product, also called plaa-som (Paludan-Müller et al., 2002; Kopermsub \& Yunchalard, 2010). Other LAB were observed in plaa-som samples, including Lactococcus garvieae, Streptococcus bovis, and Weissella cibaria in the early stages of the process and Pediococcus pentosaceus after $48 \mathrm{~h}$ into fermentation (Kopermsub \& Yunchalard, 2010). Therefore, this may describe the highest probability found for $L b$. plantarum to have great potential for GABA production in this study. However, Kim \& Kim (2012) reported one species of Weissella (Ws. viridescens) isolated from kimchi as having the capacity to synthesis GABA under in vitro conditions (Kim \& Kim, 2012).

\subsection{Effect of culture conditions for GABA products in MRS medium}

Several factors that may affect the production of GABA by Lb. plantarum L10-11 were examined in MRS medium under different conditions. As can be seen in Figure 2A, the increasing of MSG resulted in higher GABA accumulation in the culture medium and the maximum GABA content was obtained in MRS medium containing $4 \%$ MSG. Similar to the GABA production of $L b$. brevis $340 \mathrm{G}$, which was enhanced by increasing the MSG

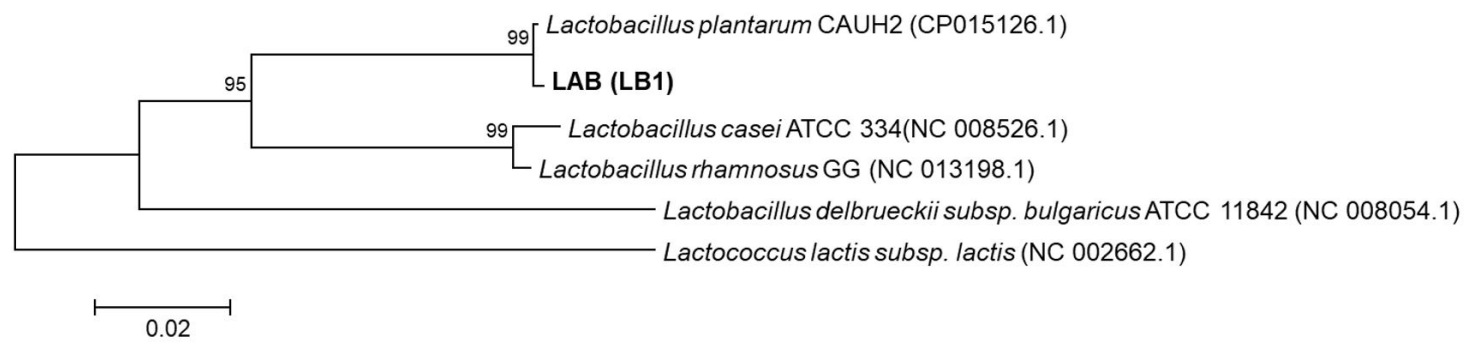

Figure 1. Phylogenetic Relationship of isolate LAB L10-11 (LB1) to a various known LAB based on 16 S rRNA sequences. The neighbour-joining phylogenetic tree was constructed with 1000 bootstap replicates. 

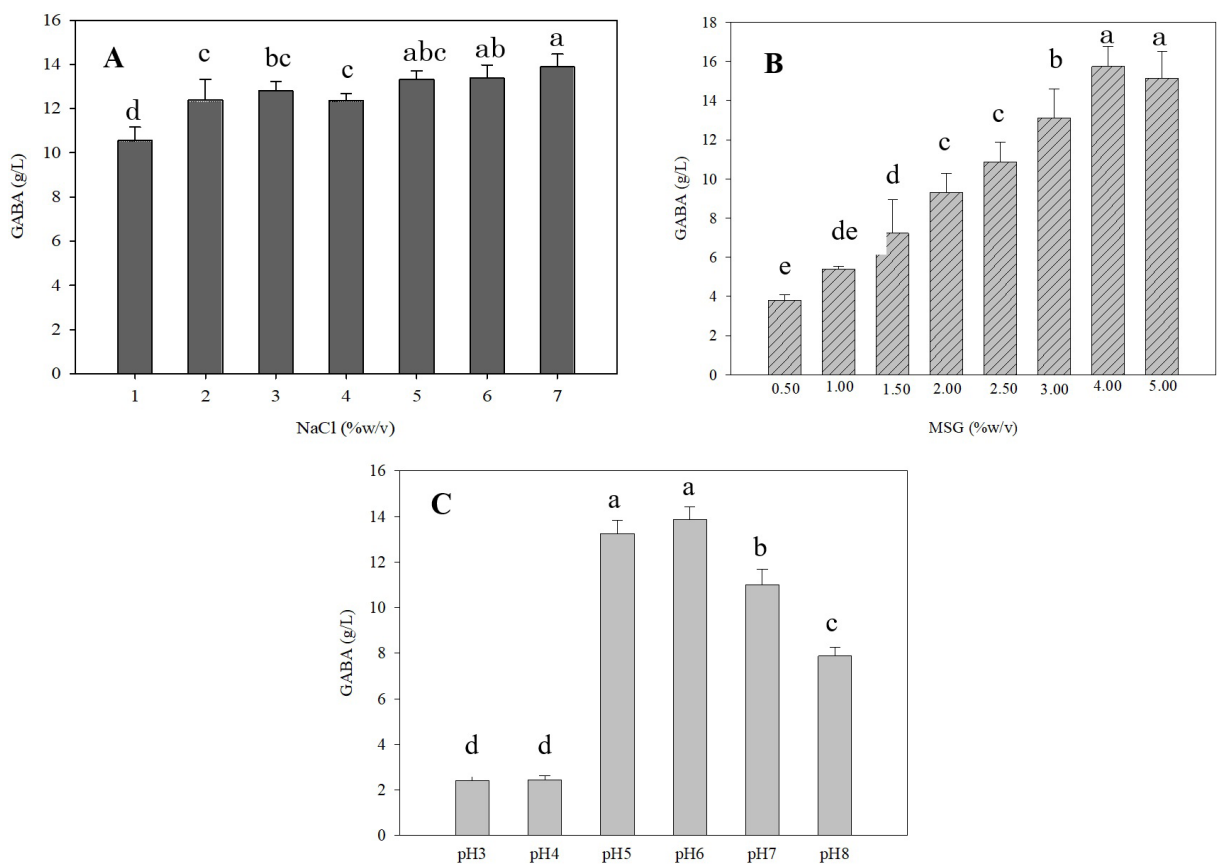

Figure 2. Effect of MSG (A), $\mathrm{NaCl}(\mathrm{B})$, and $\mathrm{pH}(\mathrm{C})$ on GABA production by Lb. plantarum L10-11. Cells were grown on MRS medium at $30{ }^{\circ} \mathrm{C}$ with different conditions as indicated. The experiment was conducted in triplicate and expressed as mean \pm standard deviation (SD). The different letters on bar indicate significant difference $(\mathrm{p}<0.05)$ between the experimental groups.

concentration up to $3 \%$ while exceeding $3 \%$ of MSG, a negative effect on GABA production was observed (Lim et al., 2013). Consistently, Shan et al. (2015) have reported that GAD activity is enhanced by the addition of L-MSG up to $75 \mathrm{mM}$. However, the yields of GABA and GAD activity are also declined above this concentration (Shan et al., 2015). Moreover, they also found that the growth yield of $L A B$ can be inhibited by a high concentration of MSG and consequently lower synthesis of GAD, thus reducing GABA production (Lim et al., 2013; Shan et al., 2015).

The influence of $\mathrm{NaCl}$ was also examined and showed that high GABA production could be maintained even at $\mathrm{NaCl}$ concentration up to $7 \%$ (Figure 2B). At lower levels of $\mathrm{NaCl}$ (1-3\%), it seemed to be able to enhance GABA production. Activation of glutamate decarboxylase (GAD) responsible for the synthesis of GABA could be observed in the presence of osmotic stress by $\mathrm{NaCl}$ or D-sorbitol (Kanwal et al., 2014). This may also be correlated with the source of isolation since salt content added in Plaa-som regularly ranges from approximately 6-11\% (Paludan-Müller et al., 2002). In addition, this strain was reported to be able to grow and produce lactic acid in MRS medium supplemented with $7 \% \mathrm{NaCl}$ (Hongsachart, 2016). Lb. buchneri isolated from Kimchi could grow at salt concentrations up to only 3\% (Cho et al., 2011). A wide range of salt tolerance would be advantageous for varieties of applications in fermented products.

The effect of initial $\mathrm{pH}$ on GABA production was determined in the MRS medium $\mathrm{pH}$ 4.0-8.0. As shown in Figure 2C, the highest GABA production was obtained from the initial $\mathrm{pH}$ of MRS in a $\mathrm{pH}$ range of 5.0-6.0. GABA production dramatically decreased at $\mathrm{pH}$ values below 4.0 or above $\mathrm{pH} 8.0$ (Figure 2C). The optimal $\mathrm{pH}$ for GABA production by different $\mathrm{LAB}$ strain was previously determined and mostly exhibited their $\mathrm{pH}$ at the acidic range of 4-6 (Dhakal et al., 2012). However, Lb. lactis produced the highest amount of GABA $(7.2 \mathrm{~g} / \mathrm{L})$ at a $\mathrm{pH}$ range from 7.5 to 8.0, while reduced GABA production was apparent at $\mathrm{pH}$ above 8.0 (Lu et al., 2008). The $\mathrm{pH}$ in the culture medium usually changes with time during fermentation (see results below). Therefore, initial $\mathrm{pH}$ affects the final GABA yield and the $\mathrm{pH}$ of the medium, which should be adjusted to maintain the optimum pH (Dhakal et al., 2012).

\subsection{Growth profile and GABA production at different temperatures}

Figure 3 shows the cell growth achieved and GABA production by $L b$. plantarum L10-11 cultured in MRS with 3\% MSG (pH 6.0) at $30^{\circ} \mathrm{C}$ and $37^{\circ} \mathrm{C}$. Its growth reached a stationary phase after $36 \mathrm{~h}$ of cultivation at both temperatures. The growth yield was not significantly different between the two temperatures level tested during exponential phase of growth. The $\mathrm{pH}$ value decreased significantly due to acid formation by this strain at exponential phase (within $24 \mathrm{~h}$ of cultivation) and increased gradually once the GABA formation started. This shows a similar trend to that reported by others (Cho et al., 2007; Sanchart et al., 2017). It can be explained that the cytoplasmic decarboxylation results in the consumption of an intracellular proton after the uptake of glutamate by its specific transporter concomitantly exporting GABA from cells by an antiporter. The net result is an increase in the $\mathrm{pH}$ of the medium (Small \& Waterman, 1998). GABA formation was drastically increased at the exponential phase, where $\mathrm{pH}$ was lowered and suitable for GAD activity. Increase in temperature from $30^{\circ} \mathrm{C}$ to $37^{\circ} \mathrm{C}$ did not affected significantly on 

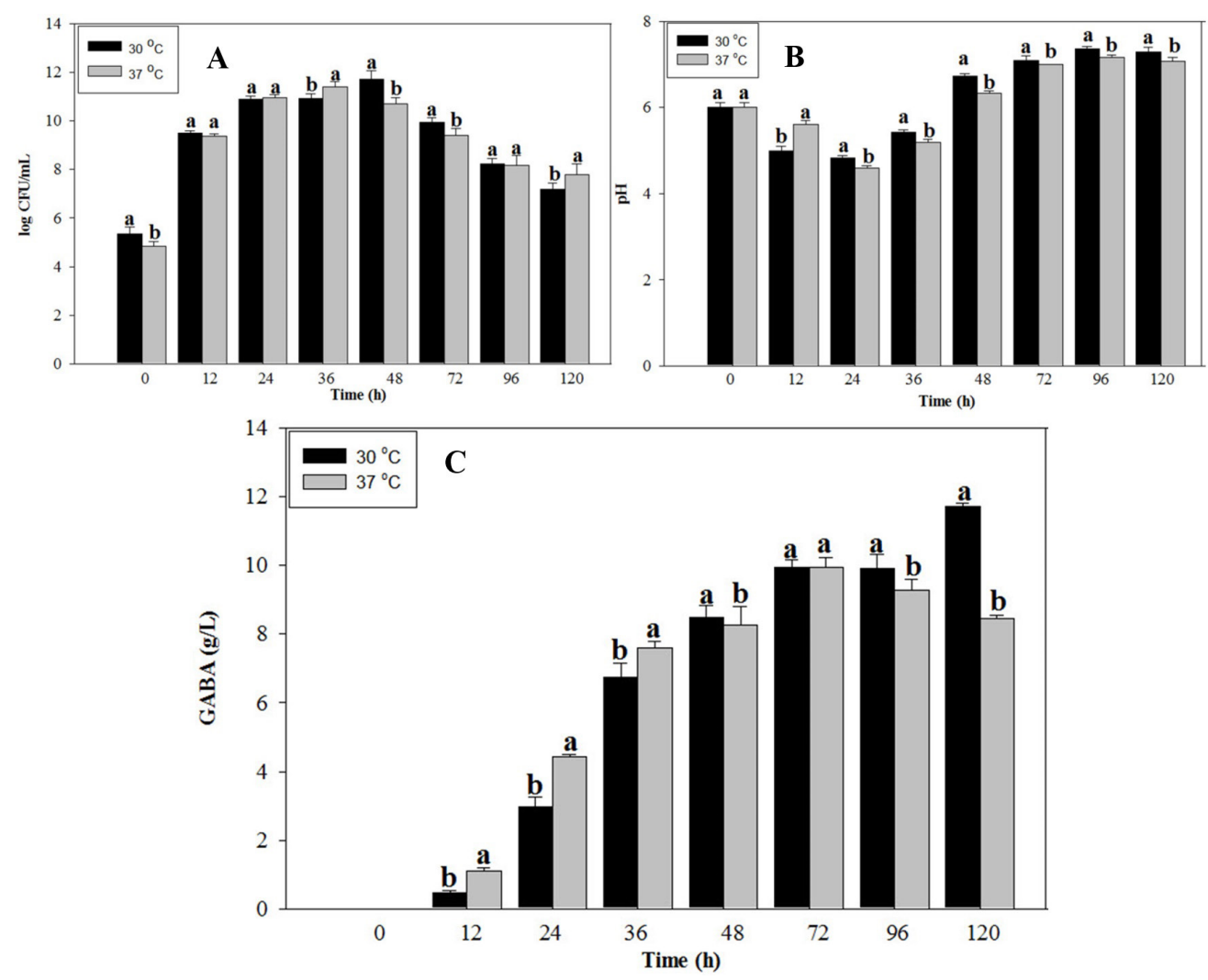

Figure 3. Time course of a cultivation of Lb. plantarum L10-11 in MRS broth containing $3 \%$ MSG at $30{ }^{\circ} \mathrm{C}(\mathrm{Grey} \mathrm{bar})$ and $37{ }^{\circ} \mathrm{C}(\mathrm{Black}$ bar). Cell viability (A), $\mathrm{pH}(\mathrm{B})$, and GABA (C) production were monitored over a period of time. The data expressed as mean \pm standard deviation (SD) from three independent experiments. The different letters on each bar (black and grey bars) indicate significant differences $(\mathrm{p}<0.05)$ between the experimental groups for Student's t-tests.

the accumulation of GABA in the culture medium when measured at $72 \mathrm{~h}$, while the GABA production was decreased significantly at $37^{\circ} \mathrm{C}$ after cultivating for $120 \mathrm{~h}$ (Figure $3 \mathrm{C}$ ). In this study, we did not examine the optimum growth temperature and GABA production clearly, although it would be below $37^{\circ} \mathrm{C}$. Lu et al. (2008) and Komatsuzaki et al. (2005) also demonstrated that the optimum production temperatures of $L$ c. lactis and $\mathrm{Lb}$. paracasei NFRI 7415 were $34^{\circ} \mathrm{C}$ and $37^{\circ} \mathrm{C}$, respectively. This suggested that different $\mathrm{LAB}$ have different optimal GABA-producing temperatures. Li \& Cao (2010) indicated that most optimal temperatures for $\mathrm{GAD}$ activities of $\mathrm{LAB}$ are within the range of $30-50{ }^{\circ} \mathrm{C}$. It is known that higher temperatures cause enzyme inactivation and cell aging. Generally, fermenting temperature ranges from $25-40{ }^{\circ} \mathrm{C}$, resulting in a high GABA yield within the temperatures (Dhakal et al., 2012).

\subsection{Use of Lb. plantarum L10-11 as starter culture for making Thai sauerkraut (Som-pak)}

Lb. plantarum has been reported to be predominant microbiota $\mathrm{LAB}$ in vegetables and consequently be responsible for the production of Kimchi and Chinese sauerkraut (Di Cagno et al., 2013). The preliminary investigation of this strain to the fermented product was in fermented vegetable, also called Som-pak, which is a homemade product also available in local open markets in Thailand, particularly in north eastern Thailand. Several vegetables can be used for mixing product, such as green onion and sprouts. However, there is no control or information for the utilisation of pure starter to improve this product. Using pure culture starter with the addition of MSG would provide an improvement in the quality and nutrition of Som-pak.

The preparation of Som-pak followed a local recipe which might be a variable in a specific area of Thailand. The pure culture of $L b$. plantarum L10-11 was inoculated at $10^{6} \mathrm{CFU} / \mathrm{g}$ in to sample with added MSG at different concentrations $(0.1,0.3$ and $1.0 \% \mathrm{w} / \mathrm{w})$ compared to the ordinary variety, which did not have any pure culture. Fermentation was carried out in a closed plastic bag for 5 days. Then, four types of Som-pak were assessed for their properties (Table 1). $\mathrm{pH}$ value was decreased at in a range of 3.4-3.7. The addition of MSG results in higher $\mathrm{pH}$ value corresponding to the high formation of GABA in Som-pak samples. On the other hand, acidity was decreased in the sample adding 1\% MSG. Viable cells of LAB among Som-pak samples showed no significant difference to the control (12-13 logCFU/g), while adding $1 \%$ MSG gave significant higher than others.

In general, Som-pak has been eaten on a daily basis in Thailand for a long time. It can be used as a probiotic food. Figure 4 shows the DPPH-scavenging activity of Som-pak, expressed as VCEAC, 
Application of gaba-producing lactic acid bacteria in som-pak

Table 1. GABA production and sensory scores of control Som-pak and Lb. plantarum L10-11 inoculated Som-pak after 5 day of fermentation.

\begin{tabular}{|c|c|c|c|c|c|c|c|c|c|}
\hline \multirow[b]{2}{*}{ Som-pak } & \multicolumn{4}{|c|}{ Characteristics } & \multicolumn{5}{|c|}{ Sensory score $^{1}$} \\
\hline & $\mathrm{pH}$ & $\begin{array}{l}\text { Acidity } \\
(\% \mathrm{w} / \mathrm{v})\end{array}$ & $\begin{array}{c}\text { GABA } \\
(\mathrm{g} / 100 \mathrm{~g})\end{array}$ & $\log C F U / g$ & color & odor & Sourness & Umami & $\begin{array}{c}\text { overall } \\
\text { acceptance }^{2}\end{array}$ \\
\hline Control & $3.49^{c}$ & $0.78^{\mathrm{b}}$ & $0.14^{\mathrm{d}}$ & $12.17^{b}$ & $6.57^{\mathrm{a}}$ & $6.1^{\mathrm{a}}$ & $6.30^{\mathrm{a}}$ & $6.37^{\mathrm{bc}}$ & $6.6^{\mathrm{ab}}$ \\
\hline $0.1 \% \mathrm{MSG}$ & $3.44^{\mathrm{d}}$ & $0.81^{\mathrm{a}}$ & $0.19^{c}$ & $12.10^{\mathrm{b}}$ & $6.77^{\mathrm{a}}$ & $6.2^{\mathrm{a}}$ & $5.33^{\mathrm{b}}$ & $5.73^{b c}$ & $6.3^{\mathrm{b}}$ \\
\hline $0.3 \% \mathrm{MSG}$ & $3.51^{b}$ & $0.75^{c}$ & $0.27^{b}$ & $12.65^{b}$ & $6.77^{\mathrm{a}}$ & $6.33^{\mathrm{a}}$ & $5.27^{\mathrm{b}}$ & $5.53^{c}$ & $6.0^{\mathrm{b}}$ \\
\hline $1 \% \mathrm{MSG}$ & $3.77^{\mathrm{a}}$ & $0.72^{\mathrm{d}}$ & $0.68^{\mathrm{a}}$ & $13.75^{\mathrm{a}}$ & $6.83^{\mathrm{a}}$ & $6.7^{\mathrm{a}}$ & $6.37^{\mathrm{a}}$ & $6.93^{\mathrm{a}}$ & $7.07^{\mathrm{a}}$ \\
\hline
\end{tabular}

${ }^{1}$ Scores were assigned numerical values from 1 (extremely weak) to 9 (extremely strong); ${ }^{2}$ Values with different letters in the same column differ significantly (p<0.05).

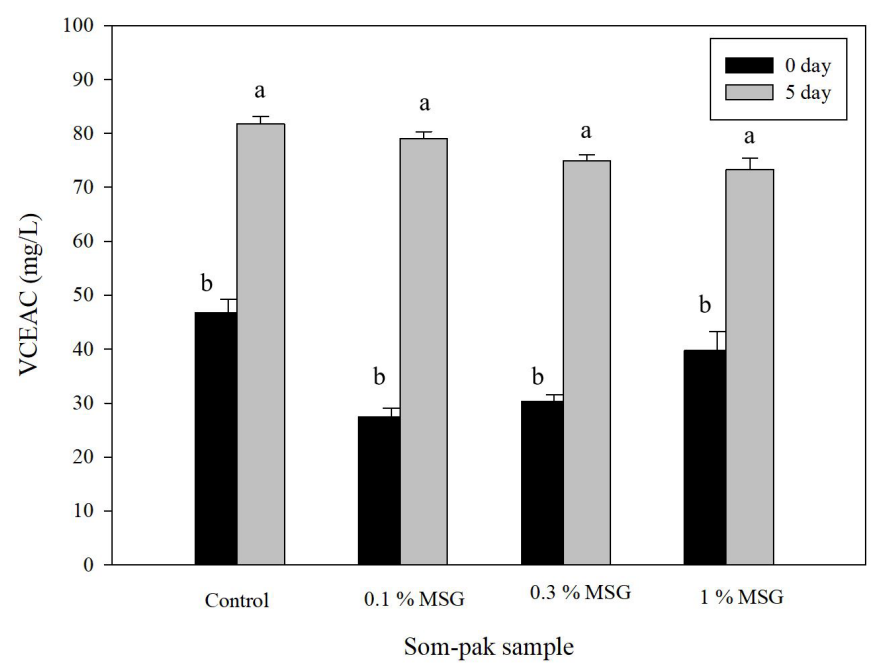

Figure 4. Vitamin C equivalent capacity (VCEAC) of Som-pak sample. The assay expressed as mean \pm standard deviation (SD) in triplicate experiments. The different letters on each bar (black and grey bars) indicate significant differences $(\mathrm{p}<0.05)$ between the experimental groups for Student's t-tests.

which donates the amount in mg of vitamin $\mathrm{C}$ equivalent per $\mathrm{mL}$ of a sample. DPPH is a relatively stable free radical that has been widely used in the investigation of antioxidant activity. It can readily submit to scavenging by an antioxidant and gets converted into 1,1-diphenyl-2-picrylhydrazine (Loganayaki et al., 2013). In this study, the development of DPPH scavenging activity expressed as vitamin $\mathrm{C}$ equivalent capacity (VCEAC) was observed during Som-pak fermentation and varies with the concentration of MSG used (Figure 4). However, DPPH value of all samples significant increased with fermentation time. A similar phenomenon was found by other researchers that measured the antioxidant activity of lactic acid bacteria (LAB) fermented skim milk (Abubakar et al., 2012). Antioxidant activity of lactic acid bacteria (LAB) fermented skim milk was determined by 1,1-diphenyl-2-picrylhydrazyl (DPPH) and ferrous chelating activity (FCA). Therefore, the results indicate that Som-pak is a good candidate as a natural antioxidant for daily life.

The sensory evaluation of Som-pak inoculated with $\mathrm{Lb}$. plantarum and added MSG at different concentrations was compared with control Som-pak by measuring sourness, odour, flavour, and general acceptability (Table 1). The sensory attributes for odour, colour and umami were not significantly $(\mathrm{p}>0.05)$ affected by inoculation of $L b$. plantarum and MSG. However, Lb. plantarum inoculation had a significant effect $(\mathrm{p}<0.05)$ on the sourness of the Som-pak product that added a low concentration of MSG $(0.1$ and $0.3 \%)$, while at $1 \%$ MSG it was the same as control. This result may correspond to the higher accumulation of GABA in Som-pak when adding 1\% MSG, resulting in significantly increase of $\mathrm{pH}$. The sourness of Som-pak may contribute to a lower score for general acceptability. However, there were no significant differences compared to control.

\section{Conclusions}

This study demonstrated that isolate $L b$. plantarum L10-11 isolated from plaa-som has great potential for GABA production. Until now, starter cultures have not been applied to improve the quality of Som-pak. The highest GABA content for the resulting Som-pak was 4 times higher than that of control when no starter was added. In addition, there was no significant effect on the overall acceptance of the products compared with control samples. Som-pak with different GABA contents and properties can be produced depending upon the starter organisms and fermentation conditions. Research to develop starter cultures of $\mathrm{LAB}$ for this fermented product would enable a more controlled process and provide a product with greater consistency in terms of quality and safety. Moreover, the discovery of a LAB strain with the ability to synthesis GABA may offer new opportunities in the design of improved, health-promoting functional foods.

\section{Acknowledgements}

This study was financial supported by Research and Technology Transfers Affairs, Khon Kean University under program KKU-NKC2560.

\section{References}

Abubakar, M. A. S., Hassan, Z., Muftah, M., \& Sharifah, N. R. S. A. (2012). Antioxidant activity of lactic acid bacteria (LAB) fermented skim milk as determined by 1,1-diphenyl-2-picrylhydrazyl (DPPH) and ferrous chelating activity (FCA). African Journal of Microbiological Research, 6(34), 6358-6364. http://dx.doi.org/10.5897/AJMR12.702.

Cho, S. Y., Park, M. J., Kim, K. M., Ryu, J. H., \& Park, H. J. (2011). Production of high $\gamma$-aminobutyric acid (GABA) sour kimchi using lactic acid bacteria isolated from Mukeunjee kimchi. Food Science and Biotechnology, 20(2), 403-408. http://dx.doi.org/10.1007/ s10068-011-0057-y.

Cho, Y. R., Chang, J. Y., \& Chang, H. C. (2007). Production of $\gamma$-aminobutyric acid (GABA) by Lactobacillus buchneri isolated from 
kimchi and its neuroprotective effect on neuronal cells. Journal of Microbiology and Biotechnology, 17(1), 104-109. PMid:18051360.

Choi, S. I., Lee, J. W., Park, S. M., Lee, M. Y., Ge, J. I., Park, M. S., \& Heo, T. R. (2006). Improvement of gamma-aminobutyric acid (GABA) production using cell entrapment of Lactobacillus brevis GABA 057. Journal of Microbiology and Biotechnology, 16, 562-568. http:// dx.doi.org/10.1007/s10068-011-0057-y.

Dhakal, R., Bajpai, V. K., \& Baek, K. H. (2012). Production of GABA ( $\gamma$-aminobutyric acid) by microorganisms: a review. Brazilian Journal of Microbiology, 43(4), 1230-1241. http://dx.doi.org/10.1590/S151783822012000400001. PMid:24031948.

Di Cagno, R., Coda, R., Angelis, M. D., \& Gobbetti, M. (2013). Exploitation of vegetables and fruits through lactic acid fermentation. Food Microbiology, 33(1), 1-10. http://dx.doi.org/10.1016/j.fm.2012.09.003. PMid:23122495.

Hagiwara, H., Seki, T., \& Ariga, T. (2004). The effect of pre-germinated brown rice intake on blood glucose and PAI-1 levels in streptozotocininduced diabetic rats. Bioscience, Biotechnology, and Biochemistry, 68(2), 444-447. http://dx.doi.org/10.1271/bbb.68.444. PMid:14981313.

Hongsachart, P. (2016). Isolation and determination of antimicrobial activity of lactic acid bacteria from fermented fish product, Pla-Som. KKU Science Journal, 44(2), 318-330.

Kanwal, S., Rastogi, R. P., \& Incharoensakdi, A. (2014). Glutamate decarboxylase activity and gamma-aminobutyric acid content in Synechocystis sp. PCC 6803 under osmotic stress and different carbon sources. Journal of Applied Phycology, 26(6), 2327-2333. http://dx.doi.org/10.1007/s10811-014-0259-9.

Kim, J. Y., Lee, M. Y., Ji, G. E., Lee, Y. S., \& Hwang, K. T. (2009). Production of $\gamma$-aminobutyric acid in black raspberry juice during fermentation by Lactobacillus brevis GABA100. International Journal of Food Microbiology, 130(1), 12-16. http://dx.doi.org/10.1016/j. ijfoodmicro.2008.12.028. PMid:19167126.

Kim, M.-J., \& Kim, K.-S. (2012). Isolation and Identification of $\gamma$-Aminobutyric acid (GABA)-producing lactic acid bacteria from Kimchi. Journal of the Korean Society for Applied Biological Chemistry, 55(6), 777-785. http://dx.doi.org/10.1007/s13765-012-2174-6.

Ko, C. Y., Lin, H.-T. V., \& Tsai, G. J. (2013). Gamma-aminobutyric acid production in black soybean milk by Lactobacillus brevis FPA 3709 and the antidepressant effect of the fermented product on a forced swimming rat model. Process Biochemistry, 48(4), 559-568. http:// dx.doi.org/10.1016/j.procbio.2013.02.021.

Komatsuzaki, N., Shima, J., Kawamoto, S., Momose, H., \& Kimura, T. (2005). Production of g-aminobutyric acid (GABA) by Lactobacillus paracase $i$ isolated from traditional fermented foods. Food Microbiology, 22(6), 497-504. http://dx.doi.org/10.1016/j.fm.2005.01.002.

Kopermsub, P., \& Yunchalard, S. (2010). Identification of lactic acid bacteria associated with the production of plaa-som, a traditional fermented fish product of Thailand. International Journal of Food Microbiology, 138(3), 200-204. http://dx.doi.org/10.1016/j. ijfoodmicro.2010.01.024. PMid:20167386.

Li, H., \& Cao, Y. S. (2010). Lactic acid bacterial cell factories for gammaaminobutyric acid. Amino Acids, 39(5), 1107-1116. http://dx.doi. org/10.1007/s00726-010-0582-7. PMid:20364279.

Li, H., Qiu, T., Gao, D., \& Cao, Y. (2010). Medium optimization for yield of gamma-aminobutyric acid by Lactobacillus brevis NCL912. Amino Acids, 38(5), 1439-1445. http://dx.doi.org/10.1007/s00726009-0355-3. PMid:19787432.

Li, Z., Zhang, L., Chen, G., Wu, L., Liu, B., Li, Y., Sun, S., Zhang, H., Zhang, Z., \& Wang, Z. (2018). A new method for comprehensive utilization of wood vinegar by distillation and liquid-liquid extraction.
Process Biochemistry, 75, 194-201. http://dx.doi.org/10.1016/j. procbio.2018.08.012.

Lim, S. I., Seo, M. J., Lee, J. Y., Nam, Y. D., Lee, S. Y., Park, S. L., Yi, S. H., Lee, M. H., Roh, S. W., \& Choi, H. J. (2013). Production of $\gamma$-aminobutyric acid by Lactobacillus brevis 340G isolated from kimchi and its application to skim milk. Food Engineering Progress, 4, 418-423. http://dx.doi.org/10.13050/foodengprog.2013.17.4.418.

Loganayaki, N., Siddhuraju, P., \& Manian, S. (2013). Antioxidant activity and free radical scavenging capacity of phenolic extracts from Helicteres isora L. and Ceiba pentandra L. Journal of Food Science and Technology, 50(4), 687-695. http://dx.doi.org/10.1007/ s13197-011-0389-x. PMid:24425970.

Lu, X., Chen, Z., Gu, Z., \& Han, Y. (2008). Isolation of $\gamma$-aminobutyric acid producing bacteria and optimization of fermentative medium. Biochemical Engineering Journal, 41(1), 48-52. http://dx.doi. org/10.1016/j.bej.2008.03.005.

Oh, S. H., Moon, Y. J., \& Oh, C. H. (2003). $\gamma$-Aminobutyric acid (GABA) content of selected uncooked foods. Journal of Food Science Nutrition, 8(1), 75-78. http://dx.doi.org/10.3746/jfn.2003.8.1.075.

Okada, T., Sugishita, T., Murakami, T., Murai, H., Saikusa, T., Horino, T., Onoda, A., Kajimoto, O., Takahashi, R., \& Takahashi, T. (2000). Effect of the defatted rice germ enriched with GABA for sleeplessness, depression, autonomic disorder by oral administration. Japanese Society for Food Science and Technology, 47(8), 596-603. http:// dx.doi.org/10.3136/nskkk.47.596.

Paludan-Müller, C., Madsen, M., Sophanodora, P., Gram, L., \& Møller, P. L. (2002). Fermentation and microflora of plaa-som, a Thai fermented fish product prepared with different salt concentrations. International Journal of Food Microbiology, 73(1), 61-70. http://dx.doi. org/10.1016/S0168-1605(01)00688-2. PMid:11883675.

Pearl, P. L., Hartka, T. R., Cabalza, J. L., Taylor, J., \& Gibson, M. K. (2006). Inherited disorders of GABA metabolism. Future Neurology, 1(5), 631-636. http://dx.doi.org/10.2217/14796708.1.5.631. PMid:23842532.

Plokhov, A. Y., Gusyatiner, M. M., Yampolskaya, T. A., Kaluzhsky, V. E., Sukhareva, B. S., \& Schulga, A. A. (2000). Preparation of gamma aminobutyric acid using $E$. coli cells with high activity of glutamate decarboxylase. Applied Biochemistry and Biotechnology, 88(1-3), 257-265. http://dx.doi.org/10.1385/ABAB:88:1-3:257.

Ratanaburee, A., Kantachote, D., Charernjiratrakul, W., \& Sukhoom, A. (2013). Enhancement of $\gamma$-aminobutyric acid (GABA) in Nham (Thai fermented pork sausage) using starter cultures of Lactobacillus namurensis $\mathrm{NH} 2$ and Pediococcus pentosaceus HN8. International Journal of Food Microbiology, 167(2), 170176. http://dx.doi.org/10.1016/j.ijfoodmicro.2013.09.014. PMid:24135673.

Sanchart, C., Rattanaporn, O., Haltrich, D., Phukpattaranont, P., \& Maneerat, S. (2017). Lactobacillus futsaii CS3, a new GABA-producing strain isolated from Thai fermented shrimp (Kung-Som). Indian Journal of Microbiology, 57(2), 211-217. http://dx.doi.org/10.1007/ s12088-016-0632-2. PMid:28611499.

Shan, Y., Man, C. X., Han, X., Li, L., Guo, Y., Deng, Y. T., Li, T., Zhang, L. W., \& Jiang, Y. (2015). Evaluation of improved $\gamma$-aminobutyric acid production in yogurt using Lactobacillus plantarum NDC75017. Journal of Dairy Science, 98(4), 2138-2149. http://dx.doi.org/10.3168/ jds.2014-8698. PMid:25622870.

Siragusa, S., Angelis, M., Di Cagno, R., Rizzello, C. G., Coda, R., \& Gobbetti, M. (2007). Synthesis of $\gamma$-aminobutyric acid by lactic acid bacteria isolated from a variety of Italian cheeses. Applied and Environmental Microbiology, 73(22), 7283-7290. http://dx.doi. org/10.1128/AEM.01064-07. PMid:17890341. 
Small, P. L., \& Waterman, S. R. (1998). Acid stress, anaerobiosis and gadCB: Lessons from Lactococcus lactis and Escherichia coli. Trends in Microbiology, 6(6), 214-216. http://dx.doi.org/10.1016/S0966842X(98)01285-2. PMid:9675796.

Soemphol, W., Adachi, O., Matsushita, K., \& Toyama, H. (2008). distinct physiological roles of two membrane-bound dehydrogenases responsible for D-sorbitol oxidation in Gluconobacter frateurii. Bioscience, Biotechnology, and Biochemistry, 72(3), 842-850. http:// dx.doi.org/10.1271/bbb.70720. PMid:18323643.

Tamura, K., Stecher, G., Peterson, D., Filipski, A., \& Kumar, S. (2013). MEGA6: molecular evolutionary genetics analysis version 6.0. Molecular Biology and Evolution, 30(12), 2725-2729. http://dx.doi. org/10.1093/molbev/mst197. PMid:24132122.
Thompson, J. D. G., Higgins, D. J., \& Gibson, T. (1994). CLUSTAL W: improving the sensitivity of progressive multiple sequence alignment through sequence weighting, position-specific gap penalties and weight matrix choice. Nucleic Acids Research, 22(22), 4673-4680. http://dx.doi.org/10.1093/nar/22.22.4673. PMid:7984417.

Ueno, H. (2000). Enzymatic and structural aspects on glutamate decarboxylase. Journal of Molecular Catalysis. B, Enzymatic, 10(1-3), 67-79. http://dx.doi.org/10.1016/S1381-1177(00)00114-4.

Watchararparpaiboon, W., Laohakunjit, N., \& Kerdchoechuen, O. (2010). An improved process for high quality and nutrition of brown rice production. Food Science \& Technology International, 16(2), 147-158. http://dx.doi.org/10.1177/1082013209353220. PMid:21339130. 